\title{
As concepções de um professor de biologia quanto ao uso de analogias na prática docente
}

Hederson Aparecido de Almeida hedersonbiologo@gmail.com orcid.org/0000-0003-2189-8094 Universidade Estadual Paulista "Júlio de Mesquita Filho” (UNESP), Bauru, São Paulo, Brasil

\section{Álvaro Lorencini Júnior} lorencinijunior@yahoo.com orcid.org/0000-0001-9365-2312 Londrina, Paraná, Brasil

\begin{abstract}
RESUMO
As analogias são recursos didáticos utilizados para facilitar a comunicação entre o professor e os alunos. Diferem de outros recursos por estabelecerem comparações entre conceitos familiares e não familiares. No ensino de Biologia é comum a apropriação das analogias pelos docentes na explicação de conceitos científicos. O presente estudo investigou quais as concepções que um professor de Biologia possui sobre o uso das analogias e sua implicação para o ensino-aprendizagem de conceitos científicos. Os dados emergiram a partir de três formas de registro: observação e gravação das aulas do professor; uma entrevista semiestruturada concedida pelo professor; e anotações feitas em um diário de campo. Os resultados mostram que o professor utiliza as analogias espontaneamente. 0 planejamento do ensino com o uso de analogias não ocorre, pois o docente não o reconhece como um recurso didático, mas sim como uma estratégia, um procedimento, uma técnica ou um mecanismo de ensino. A origem das analogias que utiliza está diretamente relacionada com as suas experiências pessoais, com o livro didático adotado, e com as analogias que os alunos compartilham em sala de aula. Uma concepção equivocada sobre o significado de analogia compromete a sua utilização de modo sistemático pelo professor. Consideramos que a investigação das concepções do professor sobre as analogias durante a sua prática docente é um caminho para que as atividades em sala de aula possam ser planejadas de modo mais consciente.
\end{abstract}

PALAVRAS-CHAVE: Concepção sobre a prática. Analogia. Ensino de Biologia. 


\section{INTRODUÇÃO}

O presente estudo é resultado de uma pesquisa de mestrado defendida em um programa de pós-graduação em educação para a Ciência de uma universidade pública do estado do Paraná, Brasil. Na oportunidade foi investigado o processo pelo qual professores de Biologia se apropriam das analogias como forma de utilizá-las como elementos da transformação de saberes eruditos em saberes escolares. A teoria de saberes que embasou o estudo foi a da Transposição Didática de Chevallard (2005). Segundo o autor, os saberes escolares não são os mesmos saberes que são difundidos nas universidades e centros científicos, pois no processo de transposição didática os saberes necessariamente passam por simplificações. Dentre os objetivos da pesquisa resgatamos o seguinte: identificar as concepções dos professores quanto a sua compreensão sobre as analogias. Os resultados obtidos por meio desta busca foram essenciais para a compreensão do papel das analogias na transposição dos saberes. Assim, este estudo é um recorte de uma pesquisa maior que traz reflexões de um professor de Biologia quanto ao uso das analogias como recurso didático.

Uma analogia segundo Glynn (1994), é uma comparação entre dois domínios heterogêneos. Há sempre um domínio familiar que nominamos como analogia ou conceito análogo e, um domínio não familiar nominado alvo ou conceito alvo. Aos domínios familiares e não familiares chamaremos, nesta pesquisa, pelos termos conceito análogo e conceito alvo, respectivamente.

As analogias no ensino de Biologia são compreendidas como comparações explícitas. Outros recursos de linguagem, como as metáforas, são consideradas comparações implícitas (LARA; GÓIS, 2012). As comparações realizadas por analogias necessitam de conectores que relacionam um domínio ao outro. Estes conectores são palavras, frases ou expressões como, por exemplo, as palavras: semelhante; que nem; como; parecido; lembra; etc. Diferentemente de uma analogia, uma metáfora caracteriza-se por uma comparação implícita entre dois domínios na forma de uma afirmação. Um modelo é uma representação de um fenômeno físico ou natural que ocorre no mundo real.

Essas diferenças entre as comparações explícitas e implícitas são reconhecidas por pesquisadores que lançam mão do recurso analógico como objeto de pesquisa. De igual modo, os pesquisadores atribuem diferentes expressões para descrevêlas: figuras de linguagem, recursos didáticos, instrumentos, facilitadores na compreensão de abstratos, dispositivos de linguagem, ferramenta, entre outros. Segundo Lara e Góis (2012), as diferentes expressões adotadas podem ter sido usadas como sinônimas pelos pesquisadores, entretanto, podem indicar diferentes formas de como são compreendidas ou concebidas pelos alunos. Compreendemos, para fins deste estudo, as analogias como recursos didáticos.

Verificar como o aluno interpreta as analogias utilizadas em sala de aula é essencial para que o professor desenvolva estratégias orientadas para seu trabalho. No entanto, não é apenas a concepção sobre as analogias dos alunos que influencia o processo de aprendizagem de conceitos, mas também a concepção do professor, uma vez que é o docente quem as utiliza como recursos didáticos.

O uso sistematizado de analogias para o ensino de conceitos científicos em 1984; GLYNN, 1994; HARRISSON; TREAGUST, 1994). Os autores entendem que se 
o professor lançar mão desse recurso deverá usá-lo conscientemente, evitando a espontaneidade. Os pesquisadores sugerem um conjunto de etapas para que o docente trabalhe com as analogias numa dada sequência. Contudo, o mais importante não é a ordem em si, e sim, que as etapas sejam cumpridas, uma vez que os professores possuem estilos diferentes de ensinar.

As concepções dos professores são permeadas por crenças, valores e conflitos advindos de suas experiências ainda na condição de estudantes. Ao iniciarem a atividade de ensino esses elementos influenciam diretamente a sua prática. A superação de crenças que dificultam o processo de ensino-aprendizagem demanda a compreensão da concepção que o professor possui sobre determinada temática e o conhecimento sobre os princípios e mecanismos que regem a prática docente quanto à utilização de forma sistematizada de recursos didáticos com múltiplas linguagens. Os estudos sob o mapeamento das concepções dos professores sobre como concebem as analogias (RIGOLON, 2008; RAMOS, 2010; FREITAS, 2011) são profícuos para o ensino à medida que possibilitam ações futuras que terão como fim mudanças significativas na prática pedagógica docente.

O presente estudo pretende contribuir para o campo de conhecimento sobre as concepções de professores quanto à utilização das analogias em sala de aula. 0 principal foco desta investigação foi identificar as concepções de um professor de Biologia sobre as analogias como recurso didático para a prática docente.

\section{PROCEDIMENTOS METODOLÓGICOS DA INVESTIGAÇÃO}

Para a realização da pesquisa obtivemos o auxílio de um professor, o qual participou do estudo como sujeito da pesquisa. O professor investigado é licenciado em Ciências Biológicas e ministrava, nos anos de 2014 e 2015, a disciplina de Biologia no ensino médio. Com a sua autorização expressa e consentida, o docente permitiu a gravação de suas aulas e posteriormente aceitou ser entrevistado. Os dados emergiram por meio de três instrumentos: o diário de campo do pesquisador, as gravações em áudio e a entrevista semiestruturada.

As gravações em áudio e o diário foram instrumentos utilizados simultaneamente, de modo que o último complementou as informações que a gravação não conseguiu captar. As observações e gravações ocorreram em uma das turmas de primeiro ano do professor. As aulas da turma observada ocorreram no período matutino. Os conteúdos ministrados ao longo das observações estavam relacionados à divisão celular, metabolismo, embriogênese e teorias de origem da vida. Os fragmentos que continham analogias foram transcritos e nominados como Episódios de Ensino com Analogias (EEA).

Após essa etapa foram selecionados dois dos 17 episódios encontrados. Utilizamos estes dois episódios como ponto central para o início da entrevista e para identificar as concepções e reflexões do docente sobre o uso de analogias no ensino de Biologia. De acordo com Minayo (2008, p. 108), a entrevista semiestruturada "[...] combina perguntas fechadas (ou estruturadas) e abertas, onde o entrevistado tem a possibilidade de discorrer o tema proposto, sem respostas ou condições prefixadas pelo pesquisador". É, acima de qualquer aspecto, uma conversa mediada entre o interlocutor e entrevistador. As 
entrevistas podem fornecer dados primários ou secundários. Os primeiros são dados que poderiam ser obtidos por outros instrumentos e os segundos são dados construídos diretamente no diálogo com o indivíduo entrevistado, tratando da reflexão sobre a realidade vivenciada pelo sujeito entrevistado.

Por compreendermos que o processo é mais importante que o resultado, utilizamos a abordagem qualitativa para o presente estudo. A escolha dessa abordagem não ocorreu ao acaso, mas foi construída mediante a natureza investigativa do trabalho, dos sujeitos envolvidos e do campo de pesquisa adotado.

Foram eleitas cinco características da pesquisa qualitativa apontadas por Bogdan e Biklen (1994). A primeira delas diz respeito ao ambiente de investigação, que é a fonte natural direta dos dados, sendo o pesquisador o principal instrumento. Neste sentido, o local escolhido foi uma escola da rede pública de ensino do norte do Paraná, na qual o sujeito da pesquisa lecionava. O primeiro contato com a escola ocorreu no mês de agosto, no primeiro ano da pesquisa em 2014, e se prolongou até o final de 2015. Essa ação foi essencial para o reconhecimento do local de coleta de dados e o estabelecimento de vínculo com o sujeito e com os outros membros da escola.

A segunda característica diz que os dados coletados são essencialmente descritivos. Assim, os dados emergiram por meio do diário de campo e dos discursos enunciados por um professor mediante a entrevista semiestruturada.

O terceiro aspecto diz respeito a darmos maior importância ao processo do que ao produto. Quando se estuda o problema o pesquisador verifica como ele se manifesta nas atividades, nos procedimentos e nas interações do dia-a-dia. Preocupamo-nos com as situações de ensino que levam o professor empregar as analogias, analisando esse processo desde o início da observação.

A quarta característica diz respeito ao significado que as pessoas dão às coisas e a sua vida. Segundo Minayo (2008), o pesquisador qualitativo trabalha com a matéria-prima das vivências como sendo as experiências dos sujeitos e a pesquisa qualitativa trabalha com o universo do significado, das crenças, dos valores e das atitudes e, portanto, é com base nesse conjunto de fenômenos que compreende e interpreta a realidade. Buscamos com a entrevista resgatar as concepções que o professor possui sobre as analogias e quais as suas reflexões quando se depara com as analogias na sua prática docente.

A última característica diz respeito à análise dos dados seguirem um processo indutivo. Isto porque não há a preocupação em buscar evidências que comprovem hipóteses definidas no início dos estudos, pois o pesquisador vai selecionando os elementos e fenômenos considerados mais importantes para ele. As abstrações vão se formando e se consolidando com base na inspeção dos dados num processo de baixo para cima (MINAYO, 2008). Adotamos, por isso, a entrevista como instrumento de constituição de dados após a análise dos fragmentos dos EEA. Fomos ao campo da pesquisa permeados por uma teoria, mas não fomos restritos, com a preocupação de confirmá-la mediante os dados encontrados. 


\section{A ENTREVISTA SEMIESTRUTURADA}

A entrevista foi realizada após a análise dos EEA. O entrevistado é licenciado em Ciências Biológicas, possui duas pós-graduações Lato Sensu na área de ensino de Ciências e é mestre em Genética e Biologia Molecular. Ministra a disciplina de Biologia em colégios públicos e privados, além de ser docente em uma instituição de ensino superior, somando uma experiência de 26 anos de magistério. Como forma de preservar a identidade do sujeito entrevistado, adotamos o nome fictício 'Paulo' como forma de referência ao professor.

Para a realização da entrevista foram necessários dois momentos. No primeiro momento foram realizadas dez questões. Antes do início da entrevista um diálogo informal entre o pesquisador e o entrevistado, permitiu que o docente tivesse ciência das questões que Ihe seriam indagadas para que o mesmo se sentisse confiante e confortável durante o processo. As questões realizadas foram as seguintes:

1- O que é uma analogia para você professor?

2- $\mathrm{O}$ que o professor acha do uso das analogias?

3- $O$ professor utiliza as analogias com frequência em sala de aula?

4- O professor planeja usar uma analogia em sala de aula?

5- Com que finalidade o professor as utiliza em suas aulas?

6- Em que momento da aula o professor utiliza as analogias?

7- O professor percebe alguma reação dos alunos quando usou as analogias nas suas explicações?

8- Como o professor avalia se o efeito do uso de determinada analogia foi negativo ou positivo?

9- Há limites para o uso desse recurso linguístico?

10- O que é levado em consideração pelo professor para usar ou não uma analogia?

No segundo momento foi solicitado ao professor ouvir o áudio dos dois fragmentos que continham os EEAs. Logo após ouvi-los, o docente respondeu as seguintes questões:

1-Neste episódio qual é a sua interpretação do que aconteceu quando você utilizou a analogia?

2- Quando o professor utilizou essa analogia o que estava imaginando?

3- Por que o professor utilizou essa analogia e não outra?

4- Após ouvir o episódio o professor acredita que essa analogia é eficaz para ensinar esse conceito científico da Biologia?

Várias respostas obtidas no segundo momento se articularam com as respostas obtidas no primeiro momento e, por isso, optamos por analisar sequencialmente as respostas dadas a segunda etapa, trazendo as respostas da primeira sempre que percebemos convergência de ideias. 
Buscamos, por intermédio desse instrumento de constituição dos dados, investigar a gênese das analogias, a concepção sobre o recurso, bem como se o professor planeja ou não o uso.

\section{ANÁLISES DOS EPISÓDIOS DE ENSINO COM ANALOGIAS}

Descrevemos a seguir as transcrições das aulas com os momentos em que identificamos a enunciação das analogias. O episódio 1 foi nominado como "o cabelinho e a vassourinha" e o episódio 2 nominado como "o carro movido a óleo?". Em cada um dos episódios identificamos os conceitos alvo e análogo trabalhados pelo professor. Descrevemos o que ocorria na aula antes e depois da analogia ser proferida. Uma descrição sucinta do conceito científico trabalhado pelo professor foi realizada, assim como a possível relação analógica pretendida pelo docente. Analisamos os dados obtidos por meio do diálogo com outras pesquisas do campo de investigação sobre as analogias no ensino de Ciências de modo geral.

Episódio 1- O cabelinho e a vassourinha

Conceito alvo: Aparelho reprodutor feminino da planta Zea sp.

Conceito análogo: Vassourinha, cabelinho

A aula a seguir ocorreu no dia 23/04/2015 e foi marcada por uma revisão para a prova. O professor trabalhou com diferentes assuntos como: reprodução, fotossíntese, respiração celular, dentre outros. Parte dos alunos ouvia atentamente, enquanto outros copiavam as anotações escritas no quadro. Em um dos momentos de exposição oral do docente uma analogia foi enunciada:

Paulo: [...] a maioria das plantas são monóicas, mas trocam material genético. Já viram pé de milho? Milho? Como é que é o pé de milho quando ele começa a florir? Tem um pendão em cima, parece uma vassourinha, parece um monte de cabelinho aqui em baixo que a gente chama de boneca. Isso aqui embaixo ((faz um desenho na lousa)) é só aparelho reprodutor feminino, lá em cima é só masculino. Então no mesmo pé de milho eu tenho o (laparelho reprodutor)) masculino e o feminino, o que é que eu tenho? Monóica, ok? $[\ldots]$.

Explicação dos conceitos: na reprodução sexuada vegetal os organismos podem ser de dois tipos: monóicos ou dióicos. São monóicos os indivíduos que possuem um único aparelho reprodutor feminino ou masculino. Indivíduos dióicos são os que possuem, em um único organismo, os dois aparelhos reprodutores (LOPES; ROSSO, 2010). O milho é uma planta monóica e o aparelho reprodutor masculino está representado pelo pendão, a parte superior da planta que contém as flores com o pólen. $\mathrm{O}$ aparelho reprodutor feminino está representado pela espiga que contém os estigmas.

Relação analógica pretendida: a estrutura do aparelho reprodutor feminino do milho Zea sp., denominada estigma, é semelhante as cerdas de uma vassoura.

Ao iniciarmos a segunda etapa da entrevista, antes mesmo de fazer a pergunta inicial, o professor Paulo fala sobre a gênese da analogia empregada como retratado no fragmento a seguir: 
Paulo: Na verdade boneca é um termo da minha vó. É sério, porque antigamente não sei se você sabe antigamente, bem antigamente minha vó já até faleceu, quando as pessoas que moravam no sítio, as meninas não tinham boneca para brincar, então elas pegavam o cabelo, o aparelho reprodutor feminino do milho e fingiam que aquilo era uma boneca, por isso que chamam de boneca. Na verdade, é que nunca expliquei isso para os alunos.

O docente revela que utiliza a analogia da boneca de milho por fazer parte de sua realidade em algum momento da vida, no caso, quando a avó contava que as crianças do sítio brincavam com a espiga de milho como boneca. O professor revelou que faz esta analogia com frequência e notamos que a sua experiência é um elemento importante no uso ou não de uma analogia. Quando responde se a origem da analogia é dos avós ele diz que essa relação analógica faz parte do conhecimento popular, principalmente dos trabalhadores rurais:

Paulo: Na verdade isso daí é meio que conhecimento popular porque se você pegar quem mora no sítio vão falar isso em dois tempos. Não é assim um conhecimento que eu adquiri só por causa da minha avó. Na época da minha avó porque os antigos falavam isso, mas quem mora no sítio fala isso aí até hoje.

Percebemos que a resposta reforça a gênese da analogia. Contudo, o grau de alcance dessa relação analógica em diferentes contextos não é o mesmo. Em uma escola rural e em uma escola urbana o significado conceitual dessa analogia será diferente. Um aluno do campo teria muito mais elementos para atribuir significado para a analogia dos cabelinhos do que um aluno advindo da cidade. Refletir se uma analogia pertence à realidade experiencial do aluno é um elemento que não pode ser desconsiderado pelo professor quando se propõem a utilizar desse recurso em sala de aula.

Respondendo a primeira questão o professor nos fornece indícios de seu reconhecimento quanto aos diferentes sentidos atribuídos pelos alunos quando utilizou a analogia:

Paulo: [...] normalmente esse termo confunde e neste sentido eu queria explicar eu acho que eu atingi porque eu não estou lembrado agora como foi o resultado dessa avaliação com eles, mas na primeira avaliação eles foram muito bem [...].

Quando o professor diz que "neste sentido eu queria explicar" notamos que ele reflete sobre a analogia que utilizou mediante a análise do seu próprio discurso. A entrevista o auxiliou no processo de reflexão sobre a sua ação. A analogia empregada parece na sua concepção dar abertura para a construção de diferentes sentidos pelos alunos. Vigotski (2009) considera que a palavra tem várias zonas de sentidos e que o significado é apenas a zona de sentido mais próxima do significado léxico da palavra. Por isso, momentos de reflexão são necessários para que o professor avalie sua prática docente no que tange uso das diferentes linguagens em sala de aula. Perguntamos ainda se o professor notou se em algum momento os alunos mencionaram os termos análogos na avaliação e a resposta foi: 
o sexuada, então eles podem até utilizar o exemplo, mas o termo tem que ser aplicado de maneira correta, né?

Quando o docente diz que "o termo deve ser aplicado de maneira correta" entendemos que há um único significado, um único sentido com o qual se propôs a trabalhar. Os objetivos ao trabalhar com esta analogia, que ele nomina como exemplo, era que o aluno se apropriasse das características do conceito análogo e transpusesse essa única característica (sentido) para o conceito alvo.

Paulo: [...] é o que falo para eles se você/se alguém chegar para você e explicar é: o caminho... sei lá... daqui para sua casa e você falar assim pega o negócio e vai andando até o treco...você não vai chegar até em casa. Então não adianta, pode utilizar, mas tem que utilizar o termo certo também, científico.

Esse fragmento demonstra uma preocupação por parte do professor em compreender se os alunos assimilaram que a analogia serviria apenas como um recurso para a compreensão do conceito científico. Duarte (2005) alerta que se corre o risco de os professores empregarem as analogias e os alunos se apropriarem apenas das características apelativas delas ou as interpretarem como o próprio conceito alvo trabalhado.

Quando o docente diz que os alunos "podem até utilizar o exemplo" percebese que não há uma definição clara para o docente do que diferencia uma analogia de um exemplo. Nesse momento da entrevista o professor utilizou dois termos com o mesmo sentido: analogia e comparação. Fazemos essa afirmação tendo como base a resposta dada para a pergunta sobre o que é uma analogia:

Paulo: Analogia quando [...] é uma comparação de um conceito científico com algum fato, algum acontecimento da vida cotidiana dos alunos. Nessa comparação [...] eu pretendo pelo menos que ele consiga entender o que eu estou querendo dizer para ele.

A "comparação" é enunciada como conceituação de analogia. O professor compreende o conceito análogo como um fato ou acontecimento do cotidiano. Por mais que não use a expressão "conceito alvo", ao falar sobre a vida cotidiana, a sua ideia é a de que os acontecimentos e os fatos são familiares aos alunos. A concepção de que o conceito científico não é familiar e o conceito análogo é familiar fica explícito no seu discurso.

Na literatura encontramos pesquisadores que investigaram a concepção de alunos e professores sobre o uso de analogias e metáforas. Rigolon (2008) verificou que o conhecimento de licenciandos de Biologia sobre analogias e sua forma de uso é muito limitada, pois confundiam a analogia com exemplo, metáfora ou modelo. Freitas (2001) encontrou resultados semelhantes ao investigar a concepção de licenciandos de Química.

O professor Paulo faz alguns apontamentos sobre as analogias que emprega. Para ele uma boa analogia é aquela que faz o aluno entender o conceito alvo. Respostas obtidas na primeira etapa da entrevista corroboram com a afirmação: 
não sabia depois que eu utilizo uma analogia e ele passa a me explicar o que ele entendeu e eu normalmente peço para eles explicarem para mim o que eles entenderam aí eu consigo entender/vê se foi bom ou se foi ruim.

Paulo: Se eu fazendo uma analogia vai facilitar o entendimento dele [...].

De igual modo, a efetividade ou não de uma analogia, na concepção do docente, depende de os alunos conseguirem explicar o conceito científico adotando a característica do análogo proposto por ele. Por meio de atividades, exercícios, discussões seria possível investigar se o objetivo proposto com a analogia foi alcançado.

\begin{abstract}
Paulo: Quando vai resolver um exercício, quando vai fazer uma discussão, quando vai fazer alguma atividade que necessite de o aluno colocar o que ele entendeu e aí eu consigo ver se ele entendeu ou não. Muitas vezes a analogia não ajudou em nada, né? Aí eu posso tentar de outro jeito, então eu vou fazer um vídeo, eu vou fazer [...] outro argumento, outro jeito de tentar fazer ele entender.
\end{abstract}

O fragmento anterior mostra que o professor tem consciência que nem sempre uma analogia é adequada para explicar um saber. E por isso que o professor parte para um "outro jeito de tentar fazer ele entender". Esse discurso nos fornece indícios de que há de sua parte uma reflexão de como o conceito análogo ajuda ou atrapalha a compreensão do conceito alvo. Essa prática reflexiva se faz necessária uma vez que o uso desses recursos pode, segundo Bachelard (1996), promover verdadeiros obstáculos epistemológicos.

O uso da relação analógica é justificado por ter sido efetiva em várias situações e pelos alunos terem a compreendido. Os fragmentos a seguir trazem elementos do discurso do docente que justificariam o uso da analogia da vassourinha/cabelinho.

\footnotetext{
Paulo: Porque essa já deu certo em várias outras situações (risos). [...] e já deu certo e isso eles entenderam.

Entrevistador: [...] o professor acredita que essa analogia é eficaz [...]? Paulo: Sim, porque eles entenderam.

Entrevistador: [...] essa compreensão o professor conseguiu avaliar como? Paulo: Na avaliação, nos comentários, na resolução de exercícios.
}

Ao afirmar que os alunos compreenderam a analogia através de atividades e da observação empírica o docente não elenca critérios mais incisivos que permita a confirmação de que houve aprendizagem dos conceitos trabalhados com o uso das analogias. Para que a afirmação "a aprendizagem de conceitos biológicos pode ser mediada pelo ensino com analogias" possa ser enunciada novas pesquisas deveriam averiguar quais os limites e potencialidades de sua utilização.

Episódio 2- O carro movido a óleo?

Conceito alvo: Água contida no sangue/corpo humano

\title{
Conceito análogo: Óleo de carro/carro
}

Em outra aula de revisão para a prova Paulo aborda sobre os aspectos da fisiologia humana. Novamente emprega uma analogia espontaneamente. 
cai o carro deve continuar trabalhando um tanto lá, mas pode estragar tudo? Pode que é o que acontece com nosso corpo. Ele continua até trabalhando, meio enroscado, mas continua, mas vai uma hora ele vai pifar que nem o carro. Não vai fundir porque não tem motor para fundir que nem o carro, mas que a gente vai pifar uma hora e vai parar de trabalhar vai... ok? [...].

Depois dessa relação analógica verbalizada não foi observado mais nenhum uso de analogia. A aula prosseguiu com a exposição oral e terminou cerca de 15 minutos após a relação analógica enunciada.

Explicação dos conceitos: a água é uma das substâncias mais importantes para a manutenção das atividades celulares. É a substância mais abundante do nosso corpo, o solvente universal (LOPES; ROSSO, 2010). Todas as reações celulares metabólicas precisam dela para ocorrer. Regula a temperatura corporal, mantendo as atividades celulares normais e a temperatura constante.

Relação analógica pretendida: da mesma forma que a água é essencial para a manutenção de todas as atividades celulares, o óleo do automóvel também seria importante para a manutenção das atividades do motor.

Adotamos a mesma dinâmica e procedimentos de análise do primeiro episódio para o segundo episódio. Quando questionado sobre como interpreta a relação analógica do fragmento Paulo diz que se preocupou em contextualizar a temática e a direcionou para alguns alunos da sala como podemos verificar no seu discurso:

\footnotetext{
Paulo: [...] eu acho que utilizei essa analogia como faz muito tempo eu posso estar meio enganada, mas acho que é isso... dentro desta turma tinham cinco alunos, cinco meninos que eram mecânicos. Entendeu? E eu percebi que eles estavam com mais dificuldades. Então essa do carro pelo que eu me lembro agora que já quase um ano isso daí, faz mais de um ano...foi ano passado, é faz mais de um ano eu não utilizei essa analogia em outras turmas, eu utilizei porque tinha aqueles cinco/ porque eles tinham mais dificuldades. Então para eles entenderem o que eu estava falando de equilíbrio, para eles entenderem que eu estava falando de ter homeostase, ficar em equilíbrio. Então foi uma coisa assim mais direcionada, se não me engano eram cinco meninos que estavam dentro da sala, tá? [...].
}

Ao perceber que seus alunos não haviam compreendido o conceito de homeostase em fisiologia humana, o professor apropria-se da analogia como forma de contextualização. $O$ docente menciona que direcionou a analogia para os cinco meninos que trabalhavam com mecânica. Na verdade, ele utilizou a analogia espontaneamente. A ideia de contextualização adotada pelo docente vai de encontro com a ideia de pertencer ao cotidiano, da atividade imediata e prática. $\mathrm{O}$ que ele atribui à contextualização é, na verdade, elementos do princípio de cotidianidade.

Quando questionado sobre a relação analógica que utilizou, Paulo reconhece que foi infeliz na sua comparação. Trouxemos algumas reflexões do docente da primeira etapa da entrevista, nas quais observamos sua atitude frente a uma analogia que não deu certo. A reflexão sobre a não eficácia da analogia, no entanto, parece ter ocorrido logo após ter escutado o áudio, na interação com o entrevistador. 
Paulo: Quando eu vejo que uma analogia que eu faço [...] não deu certo eu nunca mais uso, porque você viu que não atingiu ninguém. Então para você era uma coisa óbvia, para eles não tinha nada de óbvio nisso.

Paulo: [...] eu só queria que eles entendessem um mecanismo funcionando assim, em equilíbrio, isso que eu queria que eles entendessem, eu não ia de maneira alguma falar que a água é igual ao óleo que carro é igual a gente, de jeito nenhum. Eu só queria que eles entendessem que precisa de algumas coisas para ficar em equilíbrio e ponto.

Se pensarmos nos sentidos que os alunos poderiam ter atribuído a essa analogia elencaríamos diversas interpretações que a relação analógica poderia gerar. Por exemplo, o aluno considerar que a água no corpo tem a mesma função que o óleo no carro, o sentido de lubrificar ou que a água contida no sangue é tão viscosa quanto o óleo. Portanto, um significado pode ter diferentes sentidos (VIGOTSKI, 2009). O docente até nos apresenta alguns indícios sobre as razões que utilizou dessa relação analógica quando diz que "queria que eles entendessem que precisa de algumas coisas para ficar em equilíbrio e ponto", mas é respondendo a segunda questão que compreendemos qual foi o seu objetivo principal:

Paulo: Era para que eles conseguissem entender que se [...] se o carro [...] tem uma temperatura, se aumenta a temperatura não funciona direito, o carro tem uma engrenagem e essa engrenagem precisa de determinadas substâncias para funcionar direito e o carro tem determinadas peças [...] essa comparação que eu quis dizer com o carro.

O sentido da relação analógica que professor realizou é dúbio. Primeiro o docente diz que a função da água seria regular a temperatura e a do óleo fornecer substâncias para que as engrenagens possam funcionar. Concordamos que a água é uma substância importante para a homeostase corporal, contudo, não tem a mesma função, o mesmo sentido que o óleo possui para o carro que é de lubrificante. O próprio professor reconhece que sua analogia em outra situação não seria adequada, como evidenciado nos fragmentos seguintes:

Paulo: Não, em outras situações não, não, não. Eu só queria que eles entendessem um mecanismo funcionando assim, em equilíbrio, isso que eu queria que eles entendessem, eu não ia de maneira alguma falar que a água é igual ao óleo, que carro é igual a gente, de jeito nenhum. Eu só queria que eles entendessem que precisa de algumas coisas para ficar em equilíbrio e ponto.

Paulo: O nosso corpo não tem motor para fundir que nem o carro. É a comparação não foi...não (sinal negativo com a cabeça).

Paulo: Essa é uma analogia que foi como eu te falei eu não usei em lugar nenhum mais.

Paulo: Na verdade, ela serviu naquele momento para uma coisa pontual de novo, né? Uma coisa pontual, mas se for querer extrapolar isso daí vai dar sei lá quantas horas de discussão.

O reconhecimento por Paulo de que uma analogia não serviu para os fins que se propôs mostrou-se um passo importante para a reflexão sobre a sua prática quanto ao uso das analogias. Essa reflexão deveria perpassar em discussões na formação inicial, nos cursos de licenciatura, e inseridas nos programas de formação continuada.

Quando perguntado do por que utilizou a analogia do carro e não outra, Paulo nos aponta, novamente, que a analogia estava direcionada para os alunos que 
trabalhavam com mecânica. Ao explorarmos mais a resposta obtida surgiu duas outras questões relacionadas ao planejamento e à validade da analogia:

\begin{abstract}
Paulo: Essa foi uma analogia que eu não planejei, essa foi uma analogia que pela dúvida que ele apareceu eu pensei na hora. Então não é para extrapolar essa analogia para nada, mesmo porque eu até posso utilizar essa daí ora que eu for falar de fisiologia, que é um conteúdo que eles vão ver no segundo ano só. [...], mas eu estou lembrando aqui, eu lembro que um dos meninos depois falando comigo ele falou "é professor não é só óleo" eu falei não é só água que nós precisamos. Então eu falei do óleo e falei do mesmo jeito, que o carro não precisa só de óleo e que nós não precisamos só de água, então essa conversa depois gerou mais conversas[...].
\end{abstract}

Na frase "pela dúvida que ele apareceu eu pensei na hora" percebemos que o docente não havia preparado a priori a analogia. Esse indício mostra que para aquele conceito alvo o professor não havia pensado em nenhuma analogia até então. Fica evidente em sua fala essa ação ao dizer que "essa foi uma analogia que eu não planejei". O planejamento didático das ações a serem desenvolvidas em sala de aula é essencial para que o professor estabeleça o que, como e por quê irá ensinar. O planejamento da ação didática segundo Haidt (2003), é uma necessidade constante em todas as áreas da atividade humana, inclusive a atividade de ensino. É por meio do planejamento que o professor prever as ações e determina as atividades a serem realizadas juntas com os alunos. Em uma sala de aula há situações de ensino que mesmo com planejamento não são possíveis prever, e o professor acaba utilizando das analogias. Contudo, se o professor descrever no seu plano de ensino as analogias que irá utilizar, minimizará os efeitos negativos do seu uso espontâneo.

O planejamento também foi uma das perguntas da primeira etapa da entrevista. Paulo afirmou que não planejava e que só depois passou a planejar o uso das analogias, mas não as descrevia no seu planejamento de aula como evidenciado nos próximos fragmentos:

Paulo: [...] quando eu comecei a fazer analogia eu não planejei direito, eu não tinha/eu não planejei fazer analogia, conforme foram surgindo as dúvidas dos alunos eu queria mostrar para eles que tinham algumas coisas que acontecem na vida que dá para ser comparado. Então eu fui fazendo e hoje eu planejo, mas no começo eu não planejei, era um jeito/eu achei um caminho de tentar explicar de um jeito que eles entendessem o que eu estava falando[...]. Paulo: Hoje eu planejo as analogias, ainda existem situações que de repente uma pergunta, um questionamento que o aluno faça que eu não tinha pensado que poderia ter uma dúvida em cima disso, aí na hora eu tento criar alguma coisa, mas hoje eu já vou com algumas coisas já planejadas, a maioria delas são planejadas.

Paulo: [...] Então, se eu pegar um planejamento, por exemplo, no ((omissão do nome de uma instituição de ensino)) tem um formulário para planejamento, tem papel para planejamento, tem uma metodologia eu vou colocar na metodologia analogias, vou descrever a analogia lá? Não sei se faz muito sentido. Então, porque eu penso que o planejamento é uma ferramenta que a gente tem na escola que é pra qualquer um que pegue saber o que você está fazendo em uma sala de aula, né? Agora se eu escrever uma analogia lá, eu não sei se vai ajudar ou não [...] se vai ter alguma finalidade colocar isso no planejamento.

Ferraz (2006, p. 172) ao investigar a prática de quatro professoras de Biologia percebeu que elas não planejam seu uso "[...] as analogias apareciam de uma 
forma espontânea na hora da explicação. Geralmente, quando a professora percebia que os alunos não conseguiam compreender a explicação inicial [...]". Quanto à analogia ser espontânea, outras pesquisas (BOZELLI, 2005; DUARTE, 2005; CARMO; 2006) apontam que os professores e os alunos não sistematizam, nem planificam o uso da analogia. Os nossos dados também se aproximam dos resultados encontrados pelos pesquisadores da área de ensino de Ciências. Acrescentamos a essa discussão a observação de que mesmo utilizando de forma espontânea a analogia, ao se apropriar desse recurso, o professor procura encontrar um conceito análogo que tenha significado para o seu aluno.

Paulo ainda nos revela que considera estranho registrar as analogias no seu planejamento: "se eu escrever uma analogia lá, eu não sei se vai ajudar ou não [...] resolver alguma coisa, se vai ter alguma finalidade colocar isso no planejamento". Paulo não compreende a analogia como um recurso didático e por isso tem estranhamento em prevê-las em seu planejamento. O planejamento é uma forma de sistematizar a aula, assim, descrever que utilizará analogias não poderia ser motivo de espanto como foi para o professor.

Questionamos Paulo sobre os momentos que ele utiliza as analogias. A dúvida dos alunos foi o motivo principal para que o recurso fosse empregado. Sua fala corrobora com os dados encontrados:

\footnotetext{
Paulo: [...] Em aulas práticas também é colocado então qualquer conteúdo, no meio do exercício, no meio da explicação, no meio da aula prática, no meio de uma dinâmica, eu sempre estou utilizando, mas principalmente na hora em que o aluno tem uma dúvida.
}

Quando o docente diz que "no meio da explicação" emprega a analogia, a espontaneidade se confirma. E quando diz que é "na hora em que o aluno tem uma dúvida" as interações discursivas entre aluno e professor são evidenciadas. Contudo, quando questionado como percebe essa dúvida percebemos que os gestos têm muita importância na comunicação entre aluno e professor.

Paulo: [...] dá para entender até pela expressão que ele faz, balança a cabeça ou algum sinal que ele dê a gente percebe que ele não entendeu e principalmente na hora de fazer exercícios né?

O longo tempo de experiência de Paulo como professor de Ensino Básico e Superior, o possibilita perceber, por meio dos gestos, quando um aluno não compreendeu um assunto. Nessas situações abre mão das analogias. Os conhecimentos construídos durante a prática, no momento da atividade de ensino, fazem os professores com um longo tempo de carreira perceber situações que professores novatos ainda não conseguem perceber tão cedo. Contribuímos com as discussões sobre o papel das analogias ao afirmarmos que aproximá-las a conceitos alvos só é adequado quando o conceito análogo possui similaridades observáveis pelos discentes.

\section{APONTAMENTOS SOBRE AS CONCEPÇÕES DO DOCENTE QUANTO ÀS ANALOGIAS}

Neste momento buscamos compreender, por meio das falas de Paulo, as suas concepções quanto à utilização de analogias. 


\section{Analogias: múltiplas expressões}

Ao longo da entrevista concedida Paulo apresenta suas concepções quanto à compreensão das analogias no ensino e, em diferentes momentos, pudemos encontrar expressões que nos ajudam a compreender como o docente as interpreta:

Paulo: [...] Eu acho assim, pegar uma...vamos considerar a analogia uma técnica sei lá como é que pode ser chamado isso. Você utilizar um mecanismo e querer atingir $100 \%$ nunca vai[...].

Paulo: É uma estratégia, eu não uso só ela não dá para usar uma só, né? Paulo: O que não dá para ficar é batendo, se o aluno não entendeu daquele jeito é porque aquela técnica, aquele procedimento não foi satisfatório para ele, então vamos por outro caminho.

Os termos "técnica", "procedimento", "mecanismo" e "estratégia" são mencionados pelo professor tendo o mesmo sentido, mesmo que em seu discurso notamos certa dúvida quanto ao papel de uma analogia no funcionamento didático, reforçado pela expressão "sei lá como é que pode ser chamado isso". Embora utilize com frequência as analogias em sala de aula, ao que parece, Paulo nunca se questionou sobre a função das analogias no ensino até então. Não ter uma definição clara do termo pode acarretar em uma abordagem acanhada e equivocada do termo.

Sobre essas múltiplas concepções Lara e Góis (2012) realizaram um amplo levantamento das concepções de analogias no ensino de Ciências e encontraram diferentes expressões. Das expressões de Paulo apenas a expressão "estratégia" vai ao encontro com as expressões adotadas por pesquisadores da área. Essas múltiplas expressões nos alerta que os professores em formação continuada não possuem uma clareza do que são analogias, seja por sua definição ou por sua funcionalidade no ensino. Tal observação nos permite apontar que não há uma preparação dos professores em formação e em serviço para trabalharem com as diferentes linguagens no ensino de Ciências.

\section{A abstração e a concretude}

Em diversas passagens do trabalho trouxemos a relação da abstração com as analogias. Em fragmentos do discurso de Paulo a relação dos conteúdos com a abstração foi identificada. O primeiro fragmento foi extraído da resposta que o docente elaborou para a seguinte questão: $O$ que o professor acha do uso das analogias?

\footnotetext{
Paulo: [...] os termos científicos se a gente for pensar em Biologia para aluno de ensino médio eles não são tão corriqueiros tão fáceis de entender. Então se eu consigo fazer isso no concreto para o aluno eu acho que ele entende melhor. Porque o desenvolvimento cognitivo do nosso aluno hoje do ensino médio, no meu entendimento, está muito mais para um concreto do que para um abstrato e como os conceitos de biologia principalmente do primeiro ano, principalmente célula é um conceito muito abstrato eu pensei em transformar isso mais para o concreto para eles poderem entender.
}

Paulo atribui à analogia a função de concretude. Para ele a utilização da analogia seria uma forma de atribuir a concretude para um conceito científico 
abstrato, corroborado pela expressão "se eu consigo fazer isso no concreto para o aluno eu acho que ele entende melhor". A preocupação do professor em amenizar as formas de abstração do conceito científico relativos à célula também foi observada por Mayer et al. (2001, p. 3). Os autores revelam que "[...] o caráter microscópico e extremamente abstrato desses tópicos ressente-se das abordagens metodológicas centradas na memorização de estruturas". Os autores ainda explicam que ao ensinar esses conteúdos os professores induzem os alunos a aprenderem mecanicamente por terem dificuldades em abordar conceitos abstratos. A abstração está, então, diretamente ligada ao conteúdo que será ministrado.

Paulo: Quando eu explico e eu vejo que aquele conteúdo é muito abstrato, é muito difícil de o aluno entender. Então ao longo dos anos eu já sei mais ou menos alguns conteúdos que vão dar mais dificuldades. Então em cima desses conteúdos que normalmente geram mais dificuldades que eu faço as analogias, né? Aí eles vão entendendo o que está acontecendo.

A minimização da abstração por meio das analogias, necessária para a aprendizagem de conceitos abstratos tornando-os 'concretos', é uma concepção marcante de Paulo. A compreensão de que a analogia tem um alto poder de transformar os conceitos abstratos menos abstratos servindo como uma ponte entre abstração e concretude também pode ser observado no próximo fragmento:

Paulo: [...] se eu passo um conteúdo abstrato e ele entende, para mim está
bom. Se eu passo e ele não entende aí eu começo a fazer analogias para
melhorar/para ver se melhora essa comunicação.

Quando o conteúdo é abstrato demais e o aluno não o compreende Paulo lança mão das analogias. O professor menciona que a comunicação entre o que o aluno conhece (analogia) e o que o aluno não conhece (saber sábio) melhora à medida que utiliza o recurso didático. Abstrair é uma forma de representar as ideias e suas associações que não estão diretamente relacionados à realidade. Um conceito abstrato pode ser mais ou menos concreto dependendo do contexto. A concretude e a abstração de um conceito não são influenciadas apenas pela natureza empírica do conteúdo que o professor trabalha em sala. Depende do quanto este é significativo para o aluno.

Meksenas (1992, p. 94) diz que geralmente os professores atribuem aos conceitos concretos uma conotação positiva, pertencentes à realidade tangível. Os conceitos abstratos recebem conotações negativas, pertencentes ao imaginável, distante da realidade. $\mathrm{O}$ autor desaprova a apropriação abusiva e simplista dos termos concreto e abstrato. Para o autor concreto "[...] seria tudo aquilo que se pode atribuir um significado [...]" e abstrato "[...] a mediação que possibilita realizar a passagem de um nível de concretude a outro". Nesse contexto, o concreto é tanto o ponto de partida quanto o de chegada, mediados pela abstração. Há níveis de concretude, menor na partida e maior na chegada.

Por meio de uma relação analógica o aluno pode atribuir significados, apropriando-se de características do conceito análogo. Essa apropriação é possível se o conceito alvo for significativo para o discente, caso contrário, servirá como um entrave na construção do pensamento analógico. A capacidade do aluno de representar o conceito abstrato como conceito concreto parece ser mediada pelas analogias. Neste sentido, as analogias são mediadoras no processo de construção 
de níveis de concretude cada vez mais elevados dos conceitos científicos considerados abstratos.

A relação entre o uso de analogias para minimizar a abstração dos alunos e a contextualização foi apontado por Paulo. Ele concebe a analogia como facilitador da aprendizagem de conceitos científicos ao responder a seguinte pergunta: com que finalidade o professor as utiliza em suas aulas?

Paulo: Para facilitar o entendimento do aluno, para que ele possa ter um mecanismo mais fácil, facilitador para esse entendimento. [...] o que eu vejo nos alunos é que quando eles pegam um conteúdo muito diferente para eles muito abstrato para eles, eles querem sempre trazer para o cotidiano deles e esse mecanismo ajuda você a aprender, a gravar determinados conteúdos ou determinados conceitos.

As expressões "facilitar o entendimento do aluno" e "facilitador para esse entendimento" indica um aspecto positivo para o uso desse recurso didático por parte do docente. No entanto, para que seja efetiva uma analogia deve atender ao objetivo proposto pelo professor. Esses objetivos têm que ser planejados anteriormente à aula e inclui pensar nos saberes que poderá ensinar. Para isso, tem que levar em conta se é necessário e possível ensinar os conceitos planejados por analogias, se o análogo faz parte da realidade do aluno, se haverá múltiplas interpretações, e se diferentes sentidos poderão emergir após a sua enunciação.

\section{O aluno e as suas analogias}

Alguns excertos mostram claramente que os alunos empregam as analogias da mesma forma que o professor. Essa observação encontra-se no fragmento anterior quando Paulo diz que os alunos "pegam um conteúdo muito diferente para eles, muito abstrato para eles, eles querem sempre trazer para o cotidiano deles". O professor reconhece que os alunos são capazes de formular as suas próprias analogias no excerto seguinte:

Paulo: Então, eles fazem isso e o interessante que esse menino [...] e ele lembrou. É, e ele falou olha "gente faz assim que é melhor, está vendo óh busão" e ele começou a falar tudo que ele tinha para falar do ano passado, então de uma maneira confirmou o que eu sempre pensava que ajuda a gravar.

A analogia usada pelo aluno reforça a ideia do professor de que ao utiliza-la o aluno conseguiria gravar os conteúdos. Ao ser questionado se ele trabalha com a analogia que o aluno traz para a sala de aula o docente é categórico em dizer que sim:

Paulo: Sim, sim. Se ele me trouxer uma analogia eu posso pegar o que ele fez e melhorar, ou pegar o que ele fez e usar como exemplo, ou pegar o que ele fez e fazer ele refletir para ver o que ele fez, eu uso também e eles usam muitas vezes essas analogias em prova, mas o combinado que a gente tem é assim pode até escrever lá que nem a história do busão pode até escrever, mas eu quero os termos científicos também porque não adianta eu ficar falando o busão, o troço, o negócio e o termo cientifico some, também não pode acontecer isso. 
A preocupação do docente quanto às analogias que os alunos trazem serem "boas" é evidente no excerto: "pegar o que ele fez e melhorar" e "fazer refletir". Essa interpretação é reforçada quando o professor diz que o termo científico não pode desparecer. $O$ análogo pode ser usado, mas não em substituição ao conceito alvo.

\section{CONSIDERAÇÕES FINAIS}

Partimos do objetivo de investigar as concepções de um docente de Biologia sobre as analogias como recurso didático para prática docente. As concepções do professor sobre o que são analogias são limitadas, se considerarmos as discussões e estudos sobre a linguagem analógica no ensino de Ciências. Embora o professor investigado tenha a compreensão de que as analogias são comparações, essa definição é limitada. A limitação é reforçada quando ele confunde uma analogia com um exemplo ou uma metáfora. Se a conceituação e definição desse recurso não estiver clara para o professor corre-se o risco do senso comum se sobrepor ao conhecimento científico. Também se faz necessário a compreensão da analogia enquanto recurso didático e, por isso, a necessidade do seu planejamento.

A sistematização das analogias nas aulas de Biologia é possível quando o professor planeja e prevê o seu uso. Ao entrevistar Paulo percebemos que ele não planeja o uso do recurso didático, mas que possui um conjunto de analogias com as quais trabalha frequentemente. Se o professor não compreende a analogia como um recurso didático também não a contemplará em seu planejamento. Por isso, defendemos a proposição de que os professores de Biologia precisam, antes de lançarem mão das analogias, compreenderem-nas como um recurso didático que deve ser planejado assim como o uso do livro didático, do microscópio, de experimentos, etc.

As experiências do professor estão diretamente ligadas à escolha que ele faz das analogias que utiliza. Esta observação nos permite inferir que a origem das analogias que Paulo utiliza em sala de aula não é apenas do livro didático. A experiência no magistério de 26 anos o fez construir um conjunto de analogias que são mobilizados à medida que vai trabalhando com os conteúdos científicos. $\mathrm{O}$ uso de diferentes analogias e a sua adaptação em situações específicas propicia uma reflexão frequente quanto a sua utilização. Essa afirmação ganha sentido quando o docente afirma que já descartou o uso de determinada analogia ao perceber que a sua aplicação dificultou ainda mais a compreensão do conceito/conteúdo como qual estava trabalhando. Essa reflexão é necessária, visto que os alunos podem se apropriar de características da analogia diferentes das características com as quais o professor queria trabalhar.

Verificamos que o docente em questão utiliza as analogias espontaneamente na maioria das vezes, durante sua explicação ou quando é surpreendido com uma pergunta de um aluno que não estava preparado para responder. Quando tratando de conceitos científicos essa atitude parece recorrente principalmente quando o conceito científico é considerado abstrato. A dificuldade em trabalhar com conceitos abstratos foi mencionada pelo professor como motivo de lançar mão das analogias. Neste sentido, as analogias funcionam como elementos concretos que possibilitam aos alunos abstraírem e se apropriarem dos conceitos abstratos com base na concretude do conceito análogo. 
Como contribuições deste estudo, reforçamos que trabalhar com os elementos familiares aos alunos é um estímulo importante para a aprendizagem de conceitos biológicos que, muitas vezes, estão distantes do seu cotidiano. Para que a Biologia seja uma disciplina atrativa e que motive o aluno a se envolver cognitivamente com os conteúdos e com as discussões em sala de aula é necessário que a linguagem e a comunicação do professor sejam acessíveis. Por meio da linguagem analógica, então, é possível essa aproximação de modo a tornar a aula menos monótona e mais significativa. Contudo, a condição inicial para essa aproximação deve ser a modificação da prática docente por meio da reflexão e planejamento quanto ao uso das analogias enquanto recurso didático. 


\title{
The conceptions of a biology teacher about use of analogies on teaching practice
}

\begin{abstract}
Analogies are didactic resources used to favor the communication between teachers and students. They differ from other resources by establishing comparisons between familiar and unfamiliar concepts. In biology teaching, the appropriation of analogies by teachers is commonly used to explain scientific concepts. This study has researched which are the conceptions about analogies that biology teachers have and what are their implication for the teaching and learning process of scientific concepts. The data were obtained through from three forms of registration: observation and recording of a teacher's classes; a semistructured interview; and notes from a field diary. The results show that the teacher uses the analogies in a spontaneous way. There is no teaching planning with this resource since the teacher doesn't recognize it as a didactic resource, but as a strategy, procedure, technique or teaching mechanism. The origin of the analogies that he uses is directly related to his personal experiences, to the adopted textbook, and to the analogies that the students share in the classroom. A mistaken conception about the meaning of analogy compromises its use by the teacher in a systemic way. We consider that the investigation of teacher's conceptions about analogies, during their teaching practice, is a way to enable the classroom activities to be planned of mode more conscious.
\end{abstract}

KEYWORDS: Practice conception. Analogie. Biology teaching. 


\section{AGRADECIMENTOS}

À Capes, pela bolsa de estudos de nível de mestrado concedida.

\section{REFERÊNCIAS}

BACHELARD, G. A formação do espírito científico: contribuição para uma psicanálise do conhecimento. Rio de Janeiro: Contraponto, 1996.

BOGDAN, R.; BIKLEN, S. Investigação Qualitativa em Educação: uma introdução à Teoria e aos Métodos. Porto: Editora Porto, 1994.

BOZELLI, F. C. Analogias e Metáforas no Ensino de Física: O Discurso do Professor e o Discurso do Aluno. 2005. 234 f. Dissertação (Mestrado em Educação para a Ciência) Faculdade de Ciências, UNESP, Bauru, 2005.

CARMO, E. A. As analogias como instrumentos úteis para o ensino do conteúdo químico no nível médio. 2006. 83 f. Dissertação (Mestrado em Educação em Ciências e Matemática) UFPA, Belém, 2006.

CHEVALLARD, Y. La transposición didáctica. Del saber sábio al saber enseñado. 3. ed. Buenos Aires: Aique Grupo Editor, 2005.

CURTIS, R. V.; REIGELUTH, C. M. The use of analogies in written text. Instructional Science, Amsterdam, n. 13, p. 99-117, 1984.

DUARTE, M. C. Analogias na Educação em Ciências Contributos e Desafios. Investigações em Ensino de Ciências, 10 (1), 2005.

FERRAZ, D. F. O uso de analogias como recurso didático por professores de Biologia no ensino médio. Cascavel: Edunioeste, 2006.

FREITAS, L. P. S. R. O uso de analogias no ensino da Química: uma análise das concepções de licenciandos do curso de química da UFRPE. 2011. 197 f. Dissertação (Mestrado em Ensino das Ciências) UFPRE, Recife, 2011.

GLYNN, S. M. Teaching science with analogies: a resource for teachers and texbooks authors, Washington: National Reading Research Center, p. 9-34, 1994.

HAIDT, R. C. C. Curso de didática geral. São Paulo: Ática, 2003. 
HARRISON, A. G.; TREAGUST, D. F. (1994). Science analogies: avoid misconceptions with this sistematic approach. The Science Teacher, Normal, $n$. 61, p. 40-43, 1994.

LARA, M. S., GÓIS, J. Concepções de analogias no ensino de Ciências. In: Encontro Nacional de Ensino de Química, Salvador, 2012. Disponível em: <http://www.portalseer.ufba.br/index.php/anaiseneq2012/article/view/7446> Acesso em: 12 de junho de 2017.

LOPES, S.; ROSSO, S. BIO: volume 1. 1. ed. São Paulo: Editora saraiva, 2010.

LOPES, S.; ROSSO, S. BIO: volume 3. 1. ed. São Paulo: Editora saraiva, 2010.

MAYER, M., CARNEIRO- LEÃO, A. M. A., JÓFILI, Z., BASTOS, H. Professor mediador entre o abstrato e o concreto. In: Encontro Nacional de Pesquisa em Educação em Ciências, Atibaia, 2001. Disponível em:

<http://www.nutes.ufrj.br/abrapec/iiienpec/III\%20ENPEC.html>. Acesso em: 16 de junho de 2017.

MEKSENAS, P. As noções de concreto e abstrato: sua relação com as práticas de ensino. Revista da Faculdade de Educação, v. 18 n. 1, p. 92-98, 1992. Disponível em: <http://www.revistas.usp.br/rfe/article/view/33482>. Acesso em: 21 junho de 2017.

MINAYO, M. C. S. Pesquisa social: teoria, método e criatividade. 27.ed. Petrópolis, RJ: Vozes, 2008.

RAMOS, R. L. Analogias na educação em saúde na prática docente do ensino fundamental das escolas estaduais de Boa Vista-RR. 2010. 103 f. Dissertação (Mestrado em Ensino de Ciências e Matemática) ULBRA, Canoas, 2010.

RIGOLON, R. G. O conceito e o uso de analogias como recurso didático por licenciandos de Biologia. 2008. 132 f. Dissertação (Mestrado em Educação para as Ciência e o Ensino da Matemática) Universidade Estadual de Maringá, Maringá, 2008.

VIGOTSKI, L. S. A construção do pensamento da linguagem. Tradução Paulo Bezerra. 2. ed. São Paulo: Martins Fontes, 2009. 
Recebido: 23 mar. 2017

Aprovado: 19 jul. 2018

DOI: $10.3895 /$ actio.v3n2.8085

Como citar:

ALMEIDA, H. A.; LORENCINI-JÚNIOR, A. As concepções de um professor de Biologia quanto ao uso de analogias na prática docente. ACTIO, Curitiba, v. 3, n. 2, p. 173-194, mai./ago. 2018. Disponível em:

<https://periodicos.utfpr.edu.br/actio>. Acesso em: XXX

Correspondência:

Hederson Aparecido de Almeida

Rua Professor Francisco Antunes, n²-26, Vila Galvão, Bauru, São Paulo, Brasil.

Direito autoral: Este artigo está licenciado sob os termos da Licença Creative Commons-Atribuição 4.0

Internacional.

(c) (1) 